\title{
MODELING DRIVER BEHAVIOR FOR TWO AND THREE LANE SECTIONS IN IRAQI RURAL ROADS
}

\author{
Asst. Prof. Dr. Hamid Athab Al-Jameel, \\ University of Kufa-Civil Engineering Dep. \\ E- mail: hamed.aljameel@uokufa.edu.iq
}

\author{
Eng. Ali Jihad Kadhim, \\ Al-Mustansiriayah University-Highways and Transportation Engineering Dep. \\ E-mail: Alijkr1993@gmail.com
}

Received on 26 September 2017 Accepted on 30 October 2017 Published on 15 January 2018

DOI: 10.30772/qjes.v10i4.492

\begin{abstract}
Modeling driver behavior is the corner stone for any traffic simulation model. Driving behavior is a complex task to mimic the reality by simulation model. This study has focused on collecting field data from several rural road sites. These data include lane utilization, lane changing and headway. Then, a simulation model has been developed for representing the driver behavior at rural roads. Car-following model developed in this study is safety one. Then, lane changing hybrid model has been developed according to the suggested assumptions by previous studies and collected field data to match the real behavior. Gap acceptance model has been adopted from previous studies which show good consistency with real driver behavior through comparing with other characteristics such as lane changing and lane utilization. The developed model has been calibrated with field data and showed encouraging results.
\end{abstract}

Keywords: car-following model, lane changing model, simulation model and rural roads.

\section{INTRODUCTION}

The need to modeling the behavior of the driver comes from the desire to improve the efficiency of the driver interaction with different types of modern automated systems, after completion of the model. These systems are able to predict the future procedures and are able to solve many problems occur at different levels of traffic conditions. Moreover, these systems operate flexibly so that they can be tuned to suit different behaviors of drivers [1].

The behavior of the driver during driving is complex and varies according to the condition of the driver as well as the circumstances surrounding it either from other users of the road or characteristics of the road itself, so study the characteristics of the driver and the characteristics of the vehicle comes first to understand the interaction that occurs between the driver and the vehicle on the one hand and between vehicles on the other [2,3]. Interaction between vehicles can be defined in three terms: car-following, lane change models, and implicit model between car-following and lane change models which is gap-acceptance model [4]. Details of the models will be explained in the following sections. 


\section{AL-QADISIYAH JOURNAL FOR ENGINEERING SCIENCES}

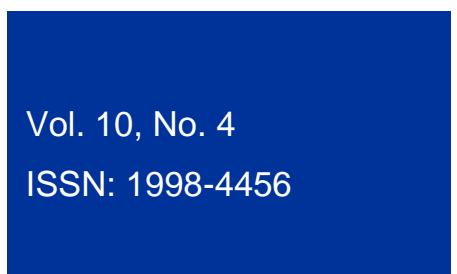

The microsimulation model is one of the tools used to understand the relationship between the three models. It focuses on the interaction between vehicles and has the ability to see the immediate results of virtual reality to implement many scenarios expected to occur on the road network. In order to determine what are the important parameters involved in building a model to understand driver behavior. It is important to define a specific algorithm for the three models to be followed as the basis for developing the simulation model $[5,6]$. The aim of the present research is to modeled and represent driver behavior in rural highway by using microsimulation technique

\section{PREVIOUS STUDIES}

It is necessary to review some of the previous studies with regard to the three models (i.e. carfollowing, lane change, and gap-acceptance models) to further understand what these models are and to prove which algorithm of these models can be used to model driver behavior to suit reality. The following sections briefly review previous studies on the three models.

\subsection{CAR-FOLLOWING}

The car-following model (CF) plays a major role in the theory of traffic flow modeling, where it is the interaction between a vehicle and another in a single lane. The introduction of this model dates back to the 1960s. Several stages of development and calibration have been carried out to make these models more reflective of reality. The safety distance model is among the most widely developed by many researchers, including Gipps [7], Benekohal and Treiterer [8], Yousif [9], and Al-Jameel [10]. The basic principle of this model is to avoid collisions between vehicles at any time of traffic and this is achieved by leaving enough space between successive vehicles.

\subsection{LANE CHANGE}

The lane change model (LC) comes in second place after the car-following model in participating in traffic flow modeling and has a close relationship with the driver's behavior, which is to change the location of the vehicle from one lane to another to achieve more comfortable driving conditions or as a result of circumstances forced the driver to change the lane, these conditions either from other users of the road or from the effects of road characteristics [11]. The lane change model is divided into a mandatory lane change (MLC) and discretionary lane change (DLC). MLC occurs when the driver is forced to change the lane or change the lane to convert to the intended destination, while DLC occurs in order to reach desirable driving conditions such as overtaking a slow vehicle [12].

\subsection{GAP-ACCEPTANCE}

In order to perform a change of lane, a motive for change must be provided and then an examination is made of whether there is an acceptable gap to achieve this. Whereas, the gap acceptance model (GA) is responsible and controls whether a change will occur to the lane or not. Among the models that have been developed is the model proposed by Wang [13], where the developed model is more reasonable for reality. In the present study, the model developed by Al-Jameel [14] was based on Wang [13] model, and Equations (1and 2) show the critical gap of lead and lag. The critical gap is the minimum time that, if available, will make the vehicle driver have sufficient time to maneuver and change his lane to another lane

[15]. Figure 1 shows the process of changing the corridor and the critical gap. 

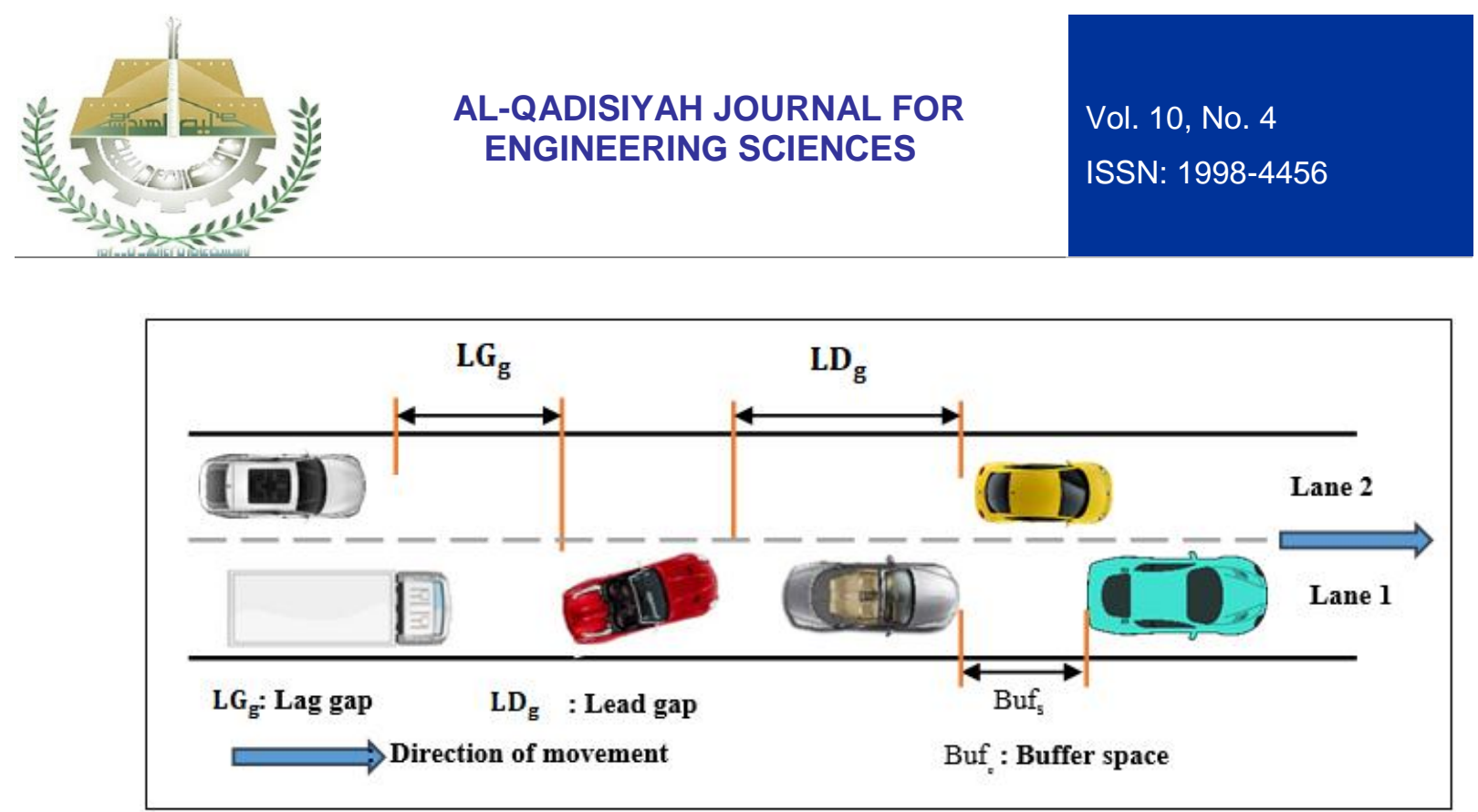

Figure 1: The process of changing the lane and the critical gap.

$$
\begin{aligned}
& \mathrm{LD}_{\text {gmin }}=\beta 1\left[\left(\mathrm{SP}_{\mathrm{L}}{ }^{2} / \mathrm{MDC}_{\mathrm{Lvt}}\right)-\left(\mathrm{SP}_{\mathrm{LCV}}{ }^{2} / \mathrm{MDC}_{\mathrm{LCv}}\right)\right]+\beta 2\left(\mathrm{R}_{\mathrm{time}}\right) \mathrm{SP}_{\mathrm{LCV}} \\
& \mathrm{LG}_{\mathrm{gmin}}=\beta 3\left[\left(\mathrm{SP}_{\mathrm{LCV}}{ }^{2} / \mathrm{MDC}_{\mathrm{LCV}}\right)-\left(\mathrm{SP}_{\mathrm{F}}{ }^{2} / \mathrm{MDC}_{\mathrm{F}}\right)\right]+\beta 4\left(\mathrm{R}_{\mathrm{time}}\right) \mathrm{SP}_{\mathrm{F}}
\end{aligned}
$$

Where; $\mathbf{S P}_{\mathbf{F}}$ is the speed $(\mathrm{m} / \mathrm{sec})$ of following vehicle.

$\mathbf{S P}_{\mathbf{L}}$ is the speed $(\mathrm{m} / \mathrm{sec})$ of leader vehicle.

$\mathbf{S P}_{\mathrm{LCV}}$ is the speed $(\mathrm{m} / \mathrm{sec})$ of lane change vehicle.

$\boldsymbol{\beta} 1, \boldsymbol{\beta} 2, \boldsymbol{\beta}$, and $\boldsymbol{\beta} \mathbf{4}$ are parameters of calibration.

$\mathbf{M D C}_{\mathbf{F}}$ is the maximum deceleration $\left(\mathrm{m} / \mathrm{sec}^{2}\right)$ for following vehicle.

$\mathbf{M D C}_{\mathrm{LC}}$ is the maximum deceleration $\left(\mathrm{m} / \mathrm{sec}^{2}\right)$ for lane changing vehicle.

$\mathbf{M D C}_{\text {Lvt }}$ is the maximum deceleration $\left(\mathrm{m} / \mathrm{sec}^{2}\right)$ for leading vehicle in the target lane, and

$\mathbf{R}_{\text {time }}$ is the reaction time (sec).

\section{DATA DESCRIPTION (DATA COLLECTION AND ANALYSIS)}

Data collection is a basic step for the calibration of the developed model and is also used to find some values of the parameters involved in the evolution of the model prior to calibration.

One of the most widely used methods of collecting traffic flow data is video recording. This method is still used to collect different data from traffic volumes, time headway, frequency of lane change and other data. The stage prior to data collection is to select suitable sites for case study. To choose sites there are several criteria adopted for this: It is essential that the site be free of curvature and grade, the site is free of roadworks and also the possibility of collecting data from the site easily. Whereas, there is a suitable place (e.g. footbridges or bridges) in order to erect a recording camera away from the driver's sight.

Table 1 describes the data collected from four sites of rural roads with normal sections. Two sites with three lanes for each direction are: The first site is The Expressway No.1 Section R4 linking Baghdad and Hilla, and the second site is the road between Baghdad and Mahmudiyah. The two sites with two lanes for each direction are the first site the road link between Najaf and Karbala and the second site the road between Baghdad and Al-Kut, as is shown in Figure 2. In addition to using the camera to record traffic, radar velocity was used to measure the desired velocity, speed measurement conducted a traffic volume less than $300 \mathrm{veh} / \mathrm{hr}[16]$.

Table 1: Details of data collection from different sits of Iraqi rural highways.

\begin{tabular}{|c|c|c|c|}
\hline Site & Direction & Recording time for each direction & Date \\
\hline
\end{tabular}




\section{AL-QADISIYAH JOURNAL FOR ENGINEERING SCIENCES}

Vol. 10 , No. 4

ISSN: $1998-4456$

\begin{tabular}{|c|c|c|c|}
\hline \multirow{3}{*}{ Baghdad-Hilla } & \multirow{3}{*}{$\begin{array}{c}\text { Both } \\
\text { direction }\end{array}$} & $5 \mathrm{hr}(08: 00 \mathrm{AM}$ to $01: 00 \mathrm{PM})$ & 22-09-2016 \\
\hline & & $3 \mathrm{hr}$ and $50 \mathrm{~min}(06: 25 \mathrm{AM}$ To 10:20 AM) & $23-10-2016$ \\
\hline & & $3 \mathrm{hr}(05: 30 \mathrm{AM}$ to $8: 30 \mathrm{AM})$ & 21-06-2017 \\
\hline \multirow{3}{*}{$\begin{array}{l}\text { Baghdad- } \\
\text { Mahmudiyah }\end{array}$} & \multirow{3}{*}{$\begin{array}{c}\text { Both } \\
\text { direction }\end{array}$} & $2 \mathrm{hr}$ and $15 \mathrm{~min}$ ( 06:45 AM To 08:55 AM) & $10-10-2016$ \\
\hline & & $3 \mathrm{hr}$ and $15 \mathrm{~min}$ ( $1: 30 \mathrm{PM}$ to $4: 40 \mathrm{PM})$ & $17-10-2016$ \\
\hline & & $3 \mathrm{hr} \quad(8: 00 \mathrm{AM}$ to $11: 00 \mathrm{AM})$ & 28-12-2016 \\
\hline \multirow[t]{2}{*}{ Baghdad-Kut } & \multirow{2}{*}{$\begin{array}{c}\text { Both } \\
\text { direction }\end{array}$} & $2 \mathrm{hr}$ and $20 \mathrm{~min}$ ( 08:30 AM To $10: 45 \mathrm{AM})$ & 27-10-2016 \\
\hline & & $2 \mathrm{hr}$ and $30 \mathrm{~min}(06: 00 \mathrm{AM}$ to $08: 30 \mathrm{AM})$ & $14-05-2017$ \\
\hline \multirow{2}{*}{ Najaf- Karbala } & \multirow{2}{*}{$\begin{array}{l}\text { Najaf to } \\
\text { karbala }\end{array}$} & $5 \mathrm{hr}(07: 30 \mathrm{AM}$ to $12: 30 \mathrm{PM})$ & $12-04-2017$ \\
\hline & & $3 \mathrm{hr}(03: 00 \mathrm{PM}$ to 6:00 PM) & 22-06-2017 \\
\hline
\end{tabular}

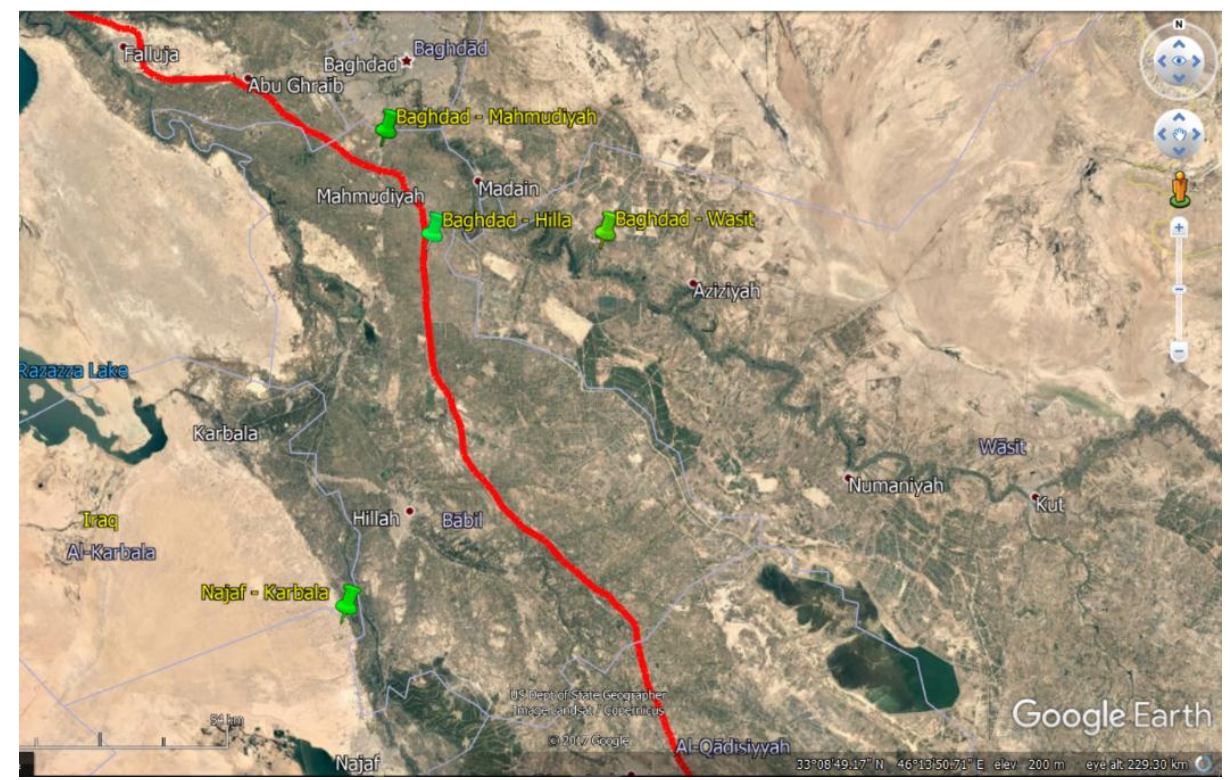

Figure 2: Data collection sites on the map.

Data analysis also took a rather long time because most data collection was done by camera recording. Vehicles were classified into two groups: Cars include passenger cars, motorcycles, taxis, small vans, and small pickups; and heave good vehicles (HGVs) include buses, lorries large van, and, trailers. Figure 3 shows the traffic volume for each of the total traffic volume and HGVs. Whereas, Figure 4 shows the traffic volume for each lane. 


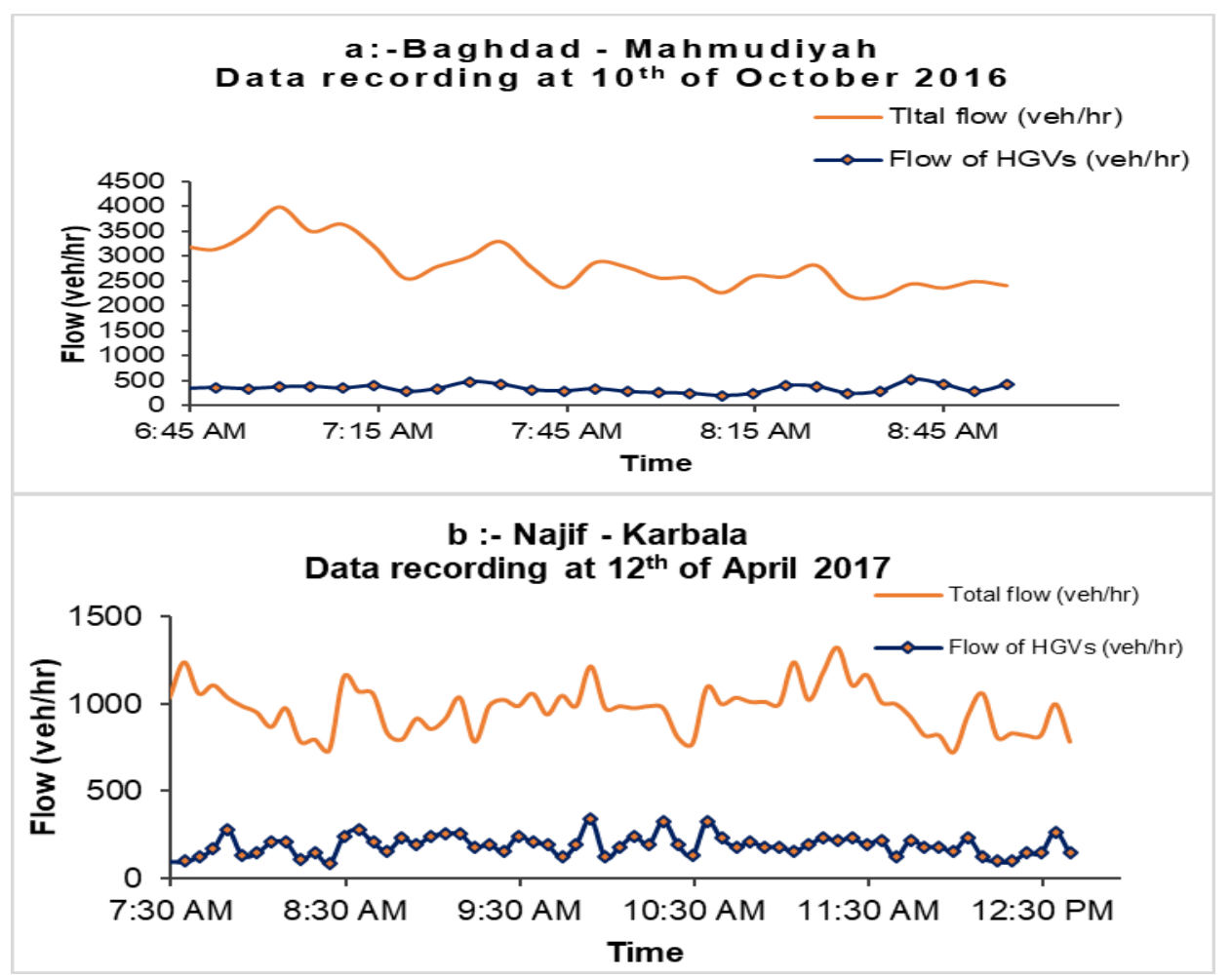

Figure 3: Total flow of vehicles and flow of HGVs (veh/hr) with time ,a-three-lane and b-two-lane. 


\section{AL-QADISIYAH JOURNAL FOR ENGINEERING SCIENCES}

Vol. 10 , No. 4

ISSN: $1998-4456$

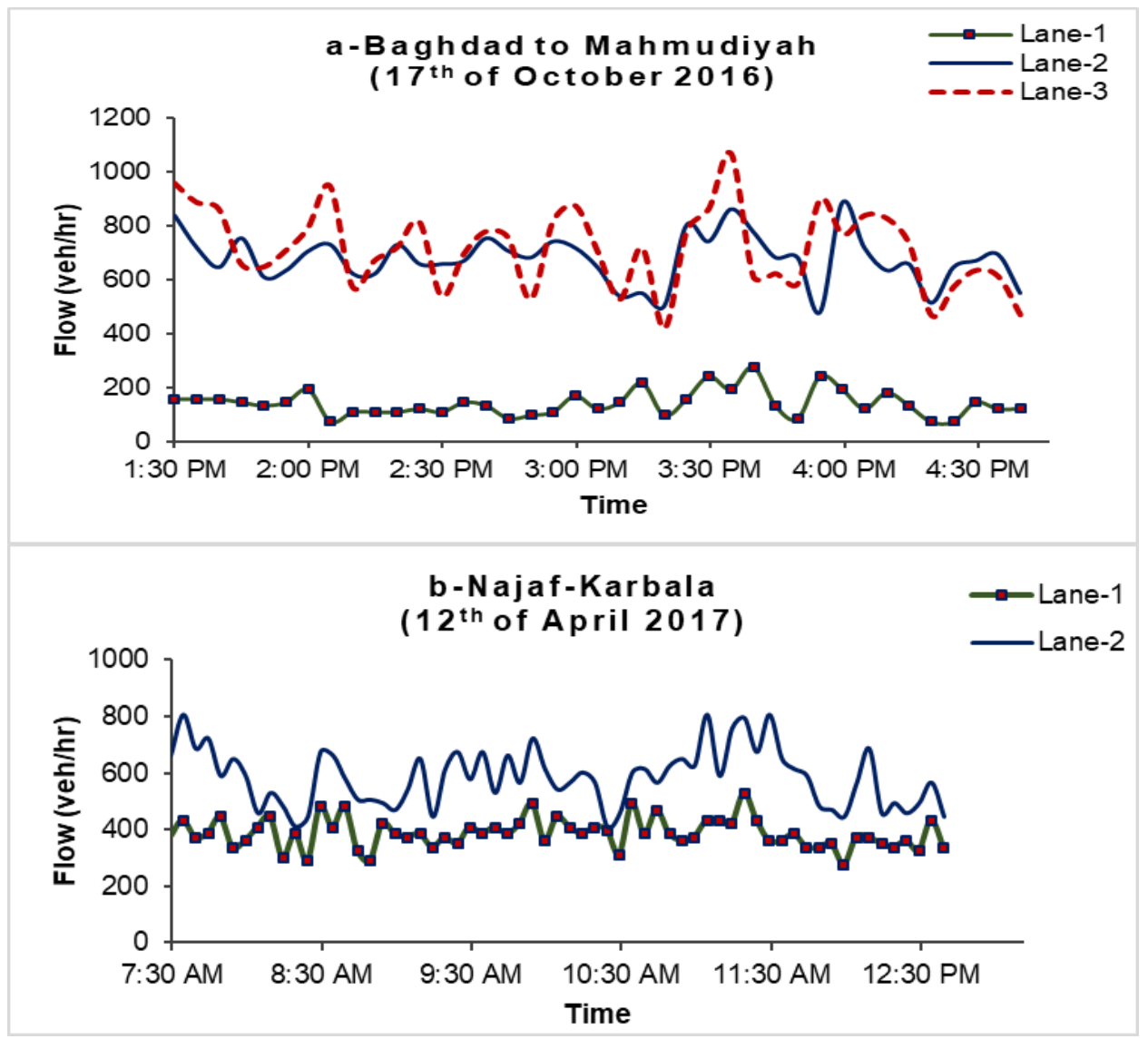

Figure 4: Flow for each lane with time (veh/hr).

\section{MODEL BUILDING AND DEVELOPMENT}

As noted in the literature review, to develop a simulation model for traffic flow, it is necessary to choose the appropriate algorithm for sub-models (CF, LC, and GA).

This study was based on the simulation model developed by Al-Jameel [14] on the roads for the UK, and was based on the code built by Al-Jameel, but was rewritten in the programming language Compaq Visual FORTRAN (version 6.6) and developed to suit the rural roads in Iraq. Figure 5. shows the general structure of the developed model and details of each step will be explained in sequence.

\subsection{MODEL PARAMETERS}

\subsubsection{Time headway}

The characteristics of both vehicle and driver should be determined either from previous studies or from on-site investigations. The characteristics are time headway, vehicle length, acceleration/deceleration rate, buffer space, desired speed, and driver reaction time.

By using a recording camera and stopwatch program, the time headway was calculated, where is the difference of time between two consecutive vehicles as they pass the same point and on the same lane. Determine the theoretical distribution that fits the distribution of field data time headway it is important in the process of generating vehicles into the system when you build a microsimulation model [17]. Figure 6 . shows the field and theoretical distribution of the data for a three-lane section where the shift negative exponential distribution was used with the shift values $0.8,0.5$ and 0.37 of the first, second and third lanes, respectively, under the volume of traffic 349(veh/hr) for the first lane, 1203(veh/hr) for the second lane, and 1651(veh/hr) 


\section{AL-QADISIYAH JOURNAL FOR ENGINEERING SCIENCES}

Vol. 10 , No. 4

ISSN: $1998-4456$

for the third lane. The Kolmogorov-Smirnov (K-S) test was used to ensure that the distribution of field data was fitting with theoretical distribution and Table 2 show the results of K-S test.

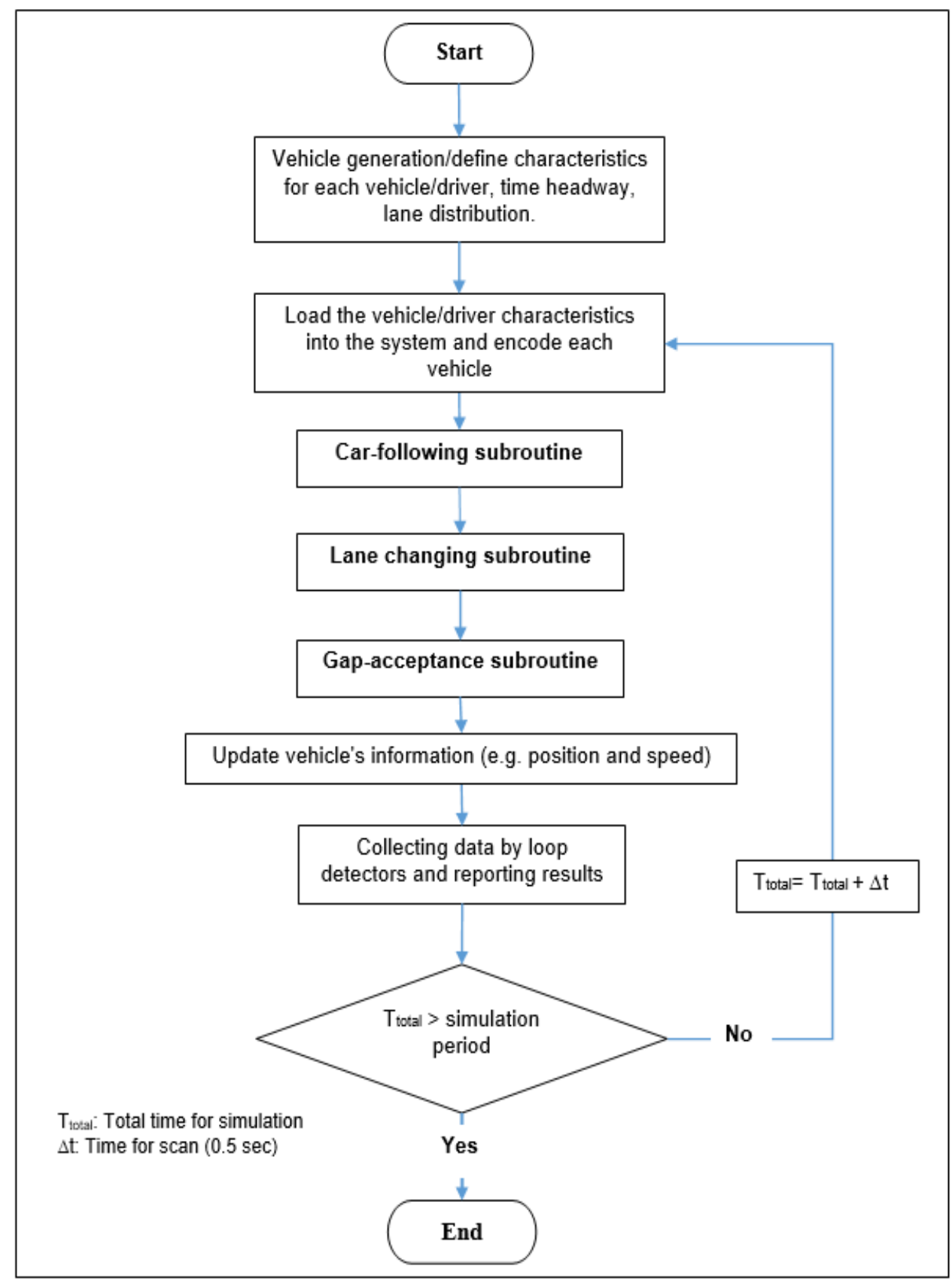

Figure 5: General flowchart for model development.

$$
H_{\text {time }}=\text { shift }-[1 / q-s h i f t] \ln (\text { RND) }
$$

Where; $\boldsymbol{H}_{\text {time }}$ : the time headway (sec).

Shift: the additional time such as $0.25,0.5$ and 1 in sec.

RND: the random number generated by sub-program, and

q: flow rate (veh/hr). 


\section{AL-QADISIYAH JOURNAL FOR ENGINEERING SCIENCES}

Vol. 10, No. 4

ISSN: $1998-4456$

Table 2: Kolmogorov-Smirnov results for testing the time headway distribution.

\begin{tabular}{|c|c|c|c|}
\hline \multirow{2}{*}{ Kolmogorov-Smirnov test (K-S) } & \multicolumn{3}{|c|}{ Site: Baghdad-Mahmudiyah (10-10-2016) } \\
\cline { 2 - 4 } & First lane & Second lane & Third lane \\
\hline Flow (veh/hr) & 349 & 1203 & 1651 \\
\hline $\mathbf{D}_{\max }$ (shift negative exponential \\
distribution) & 0.042 & 0.051 & 0.040 \\
\hline $\mathbf{D}_{\text {cr }}$ (Critical value) & 0.103 & 0.057 & 0.048 \\
\hline
\end{tabular}

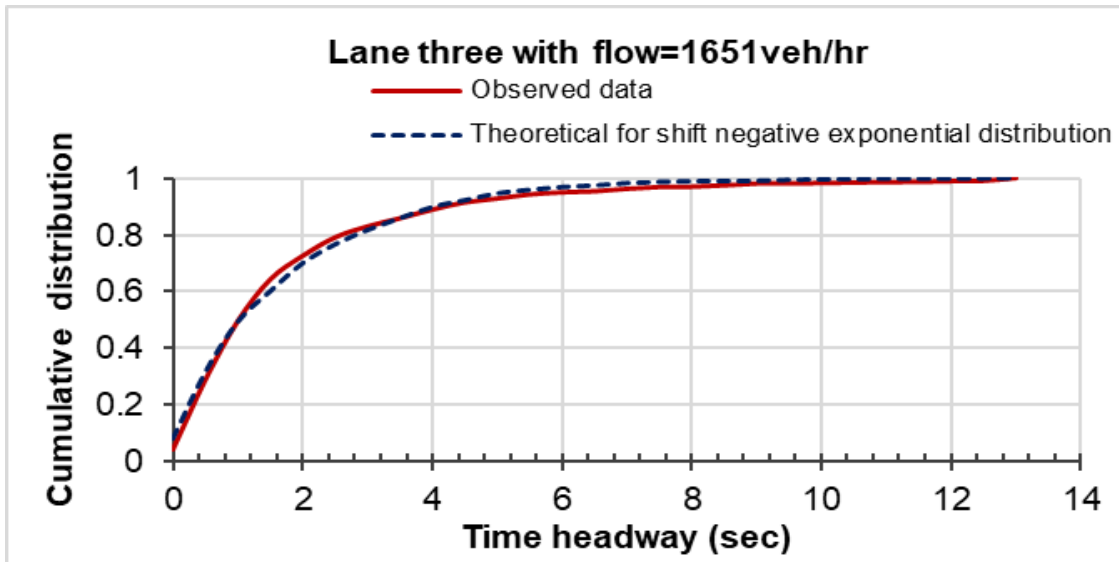

Figure 6: Observed and theoretical cumulative distribution of time headways for lane-3 with shift=0.37.

\subsubsection{Vehicle lengths}

The distribution of the length of vehicles on the road can be calculated by sensors implanted on the road surface. Due to the lack of these sensors in the Iraqi roads, the task of calculating the length of vehicles is not possible at the present time. Therefore, it was based on a previous study conducted by Al-Hanna (1974) in UK and Table 3 shows the mean length of vehicles for both cars and HGVs, where Al-Hanna found that the distribution of the length of vehicles fit with the normal distribution.

\subsubsection{Acceleration/deceleration rate}

With regard to the rate of acceleration/deceleration, there are two types of acceleration used according to ITE (1999) and is the normal acceleration (i.e. comfortable acceleration) and the maximum acceleration rate, where the normal acceleration used for example to reach the desired speed, while the maximum acceleration rate used in the case of stop the vehicle suddenly. Table $\mathbf{4}$ and $\mathbf{5}$ show the values of acceleration/deceleration according to the ITE (1999).

Table 3: Length of vehicles by Al-Hanna (1974).

\begin{tabular}{|c|c|c|}
\hline Category of vehicle & Mean $(\mathrm{m})$ & Standard deviation $(\mathrm{m})$ \\
\hline Cars & 4.2 & 0.2 \\
\hline HGVs & 11.2 & 2.4 \\
\hline
\end{tabular}




\section{AL-QADISIYAH JOURNAL FOR ENGINEERING SCIENCES}

Vol. 10 , No. 4

ISSN: $1998-4456$

Table 4: Normal acceleration/ deceleration rate (m/sec2), according to ITE [18]

\begin{tabular}{|c|c|c|}
\hline Category of vehicle & Acceleration $\left(\mathrm{m} / \mathrm{sec}^{2}\right)$ & Deceleration $\left(\mathrm{m} / \mathrm{sec}^{2}\right)$ \\
\hline Cars & 1.1 & 3.0 \\
\hline HGVs & 0.37 & 1.8 \\
\hline
\end{tabular}

Table 5: Maximum acceleration/deceleration rates $(\mathrm{m} / \mathrm{sec} 2)$ with speed value [18].

\begin{tabular}{|c|c|c|c|c|c|c|}
\hline \multirow{2}{*}{$\begin{array}{c}\text { Acceleration } \\
\left(\mathrm{m} / \mathrm{sec}^{2}\right)\end{array}$} & Speed $(\mathrm{km} / \mathrm{hr})$ & $0-32$ & $32-48$ & $48-64$ & $64-80$ & $>80$ \\
\cline { 2 - 7 } & Cars & 2.3 & 2.0 & 1.8 & 1.6 & 1.4 \\
\cline { 2 - 7 } & HGVs & 0.5 & 0.4 & 0.2 & 0.2 & 0.1 \\
\hline $\begin{array}{c}\text { Deceleration } \\
\left(\mathrm{m} / \mathrm{sec}^{2}\right)\end{array}$ & 4.9 for cars and HGVs [9] \\
\hline
\end{tabular}

\subsubsection{Buffer space}

The buffer space $\left(B_{\mathrm{SU}}\right)$ or the distance between stopped vehicles under congestion condition, as shown in Figure 1, and was adopted $1.7 \mathrm{~m}$ as its initial values for the buffer space which is subsequently adjusted by the calibration process.

\subsubsection{Desired speed}

The desired speed measurement was done by using a speed gun. Table 6 shows the rate of speed for a three-lane section, and by chi-square, the data distribution is tested and it is found to be fit with normal distribution. Figure 7 shows the normal distribution of desired speed for the second lane (cars and HGVs).

Table 6: Desired speed measurement from the site of Baghdad-Hilla (data collection on 21-06-2017).

\begin{tabular}{|c|c|c|c|c|c|c|}
\hline \multirow{2}{*}{ category } & \multicolumn{2}{|c|}{ Lane } & \multicolumn{2}{c|}{ Lane 2 } & \multicolumn{2}{c|}{ Lane 3 } \\
\cline { 2 - 7 } & $\begin{array}{c}\text { Mean } \\
(\mathrm{km} / \mathrm{hr})\end{array}$ & $\begin{array}{c}\text { St.Dv. } \\
(\mathrm{km} / \mathrm{hr})\end{array}$ & $\begin{array}{c}\text { Mean } \\
(\mathrm{km} / \mathrm{hr})\end{array}$ & $\begin{array}{c}\text { St.Dv. } \\
(\mathrm{km} / \mathrm{hr})\end{array}$ & $\begin{array}{c}\text { Mean } \\
(\mathrm{km} / \mathrm{hr})\end{array}$ & $\begin{array}{c}\text { St.Dv. } \\
(\mathrm{km} / \mathrm{hr})\end{array}$ \\
\hline Cars & 88.9 & 18.2 & 118 & 24 & 132.8 & 22.0 \\
\hline HGVs & 78.2 & 16.0 & 90.4 & 16.3 & 94.7 & 16.4 \\
\hline
\end{tabular}



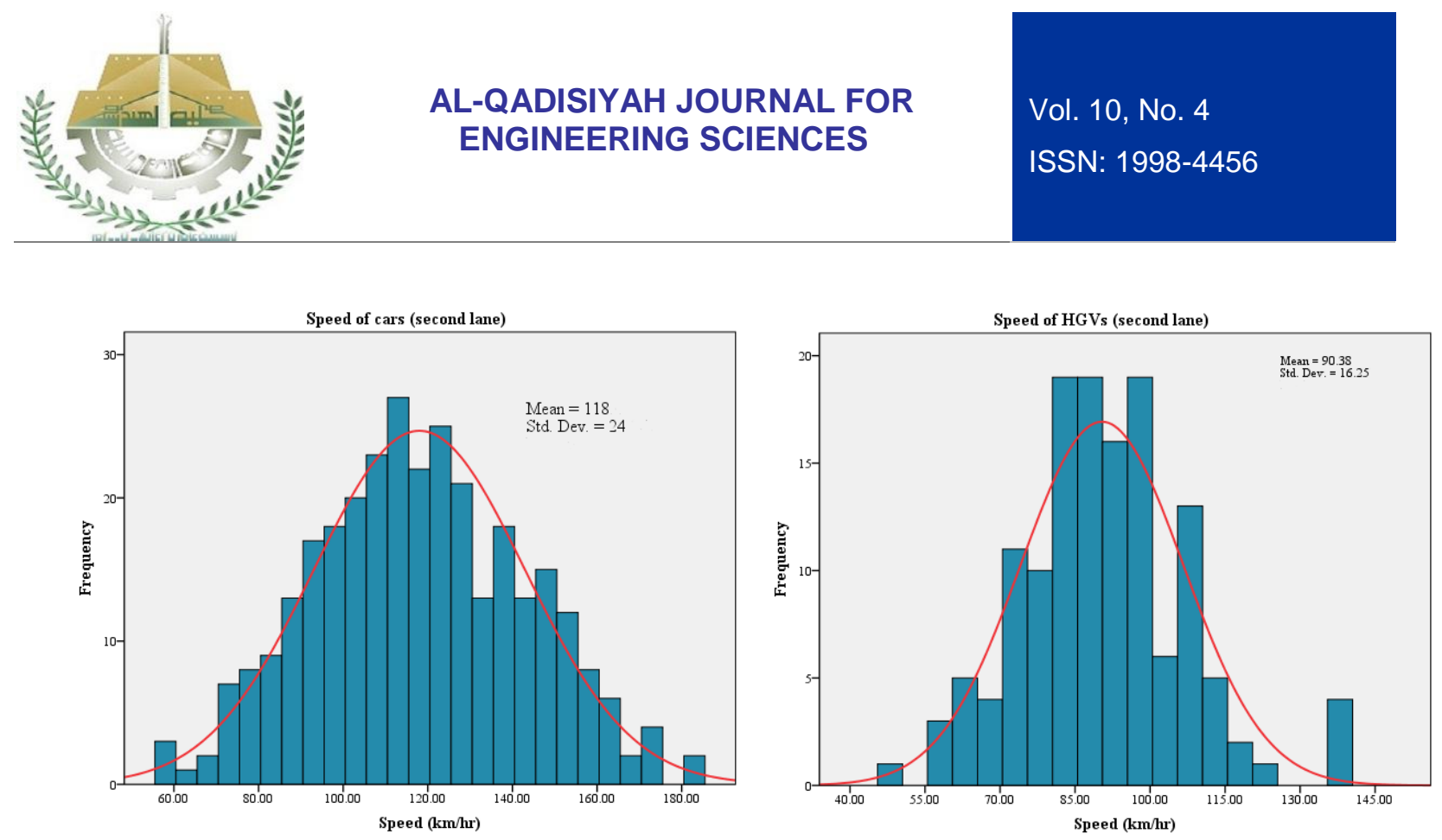

Figure 7: Normal distribution of speed.

\subsubsection{Reaction time}

The reaction time of the driver in both cases (i.e. surprised and alerted) was adopted from a previous study as suggested by Johansson and Rumar [19] and Figure 8 shows the cumulative distribution of reaction time.

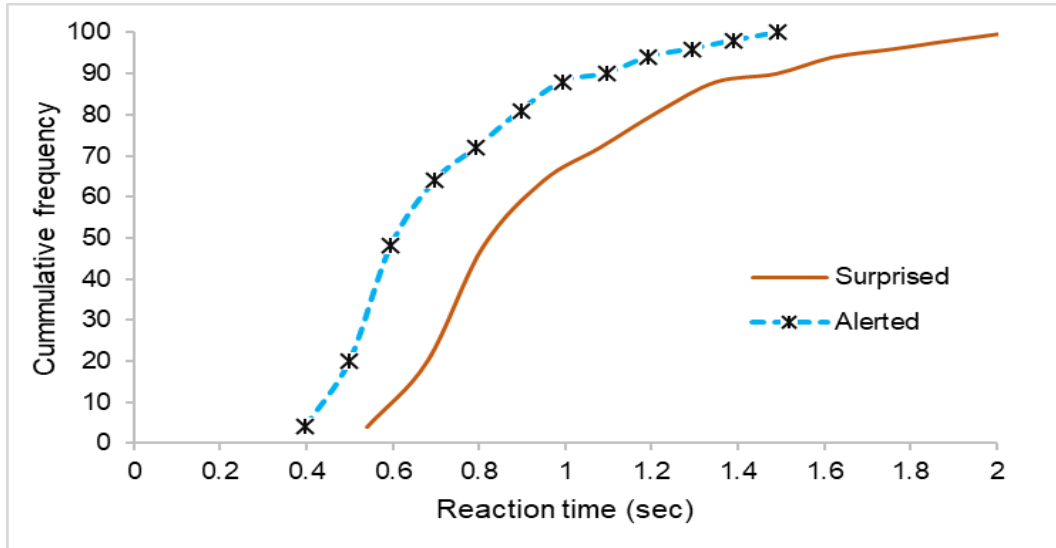

Figure 8: The cumulative distribution of the reaction time of the driver, according to Johansson and Rumar [18].

\subsubsection{Traffic distribution}

As for the distribution of vehicles on each available lane, the traffic volume of each lane was calculated. Due to the absence of loop detectors for the purpose of collecting enough data to determine the distribution of vehicles on each lane correctly, the data was collected by recording the camera towards determining the distribution of vehicles on each lane. Therefore, all data obtained were combined into a single data set for each of the three-lane and two-lane section.

Figure 9 shows the distribution of vehicles for a three-lane section, where the distribution of vehicles on the second and third lane is higher than the distribution on the first lane. This is why most drivers avoid using the first lane because of the large number of surface defects [20], which increases the traffic volume on the second and third lane.

As for the two-lane section, the distribution of vehicles on the second lane is higher of its distribution on the first lane as shown in Figure $\mathbf{1 0}$ because of the behavior and desire of the driver. Table 7 


\section{AL-QADISIYAH JOURNAL FOR ENGINEERING SCIENCES}

Vol. 10, No. 4

ISSN: $1998-4456$

summarizes the equations obtained by the Excel program, noting that the data was filtered from some abnormal data to strengthen the relationship. As for the distribution of HGVs on each lane, at this stage of the research and based on the site's investigations, it was based on a fixed percentage from the total traffic flow $(\mathrm{HGVs} \%=0.20)$.

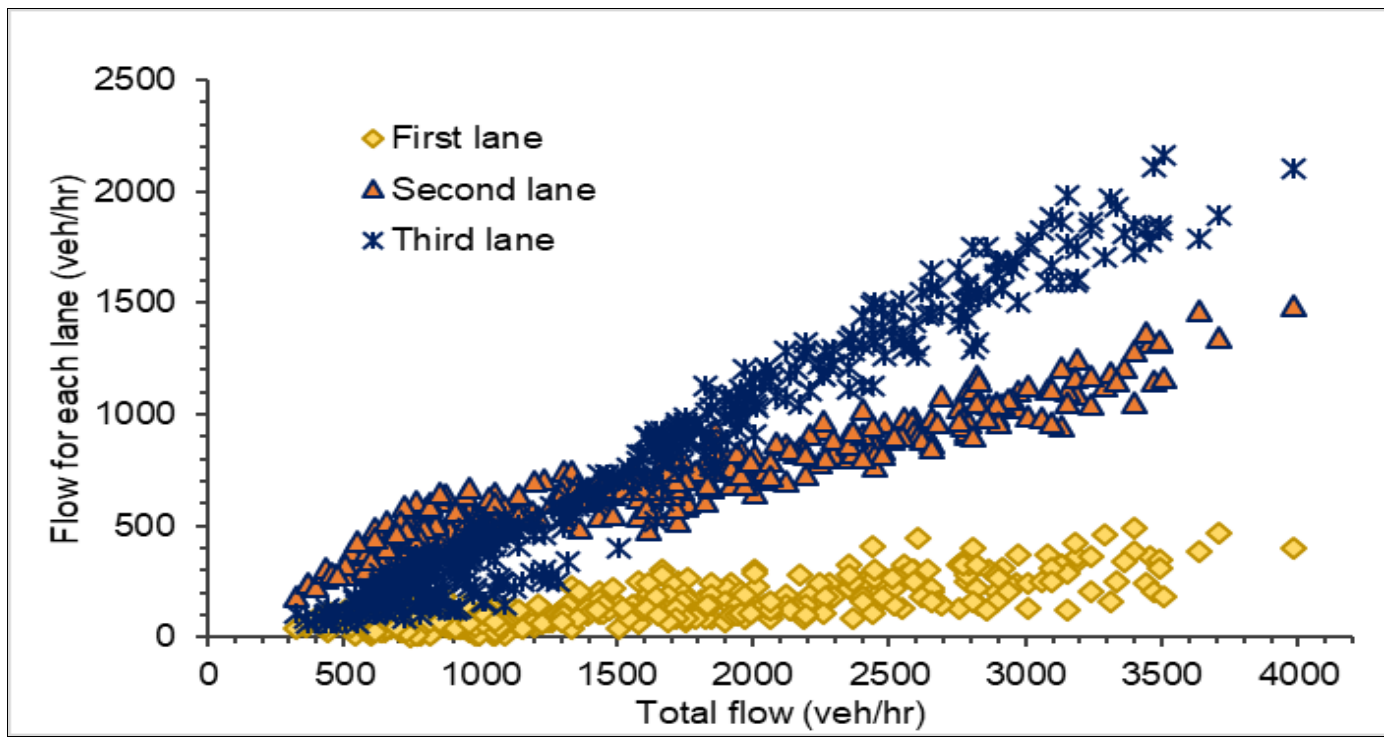

Figure 9: Distribution of vehicles per lane for a three-lane section.

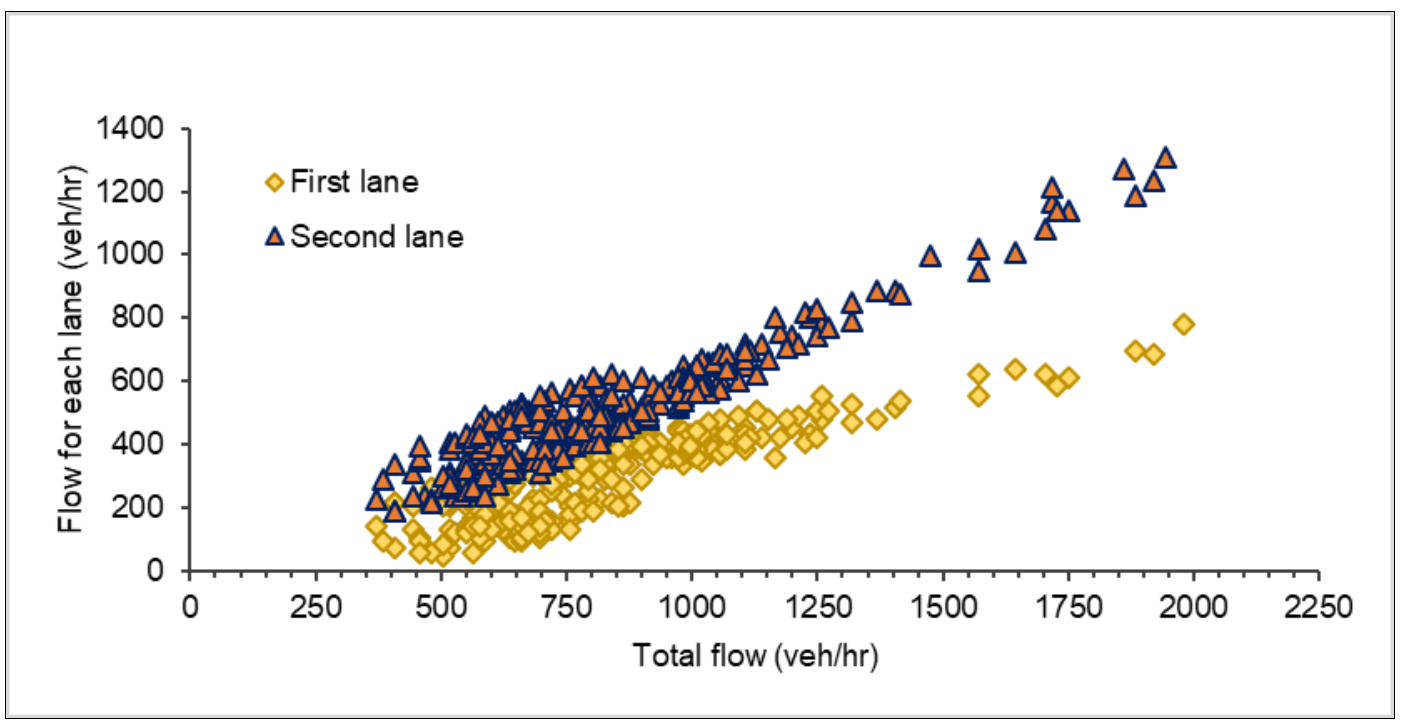

Figure 10: Distribution of vehicles per lane for a two-lane section. 


\section{AL-QADISIYAH JOURNAL FOR ENGINEERING SCIENCES}

Vol. 10, No. 4

ISSN: $1998-4456$

Table 7: Estimated equations of field data.

\begin{tabular}{|c|c|c|}
\hline Section & Equation & $\mathbf{R}^{2}$ \\
\hline \multirow{3}{*}{$\begin{array}{l}\text { Three-lane } \\
\text { section }\end{array}$} & $Q_{\text {lane-1}}=Q_{\text {total }}-Q_{\text {lane -2 }}-Q_{\text {lane-3 }}$ & --- \\
\hline & $\begin{array}{l}Q_{\text {lane-2 }}=0.2864^{*} Q_{\text {total }}+210.85 \\
\quad \text { for } Q_{\text {total }} \geq 315 \mathrm{veh} / \mathrm{hr}\end{array}$ & 0.93 \\
\hline & $\begin{array}{c}Q_{\text {lane-3 }}=0.63495^{*} Q_{\text {total }}-242.5 \\
\quad \text { for } Q_{\text {total }} \geq 385 \mathrm{veh} / \mathrm{hr}\end{array}$ & 0.96 \\
\hline \multirow{2}{*}{$\begin{array}{l}\text { Two-lane } \\
\text { section }\end{array}$} & $Q_{\text {lane-1 }}=Q_{\text {total }}-Q_{\text {lane -2 }}$ & --- \\
\hline & $Q_{\text {lane }-2}=0.0001^{*} Q_{\text {total }}{ }^{2}+0.342^{*} Q_{\text {total }}+124.1$ & 0.92 \\
\hline
\end{tabular}

${ }^{*} \mathrm{Q}=$ flow $(\mathrm{veh} / \mathrm{hr})$

\subsection{MODEL RULES}

In this section, sub-models and hypotheses used in the development of the model are identified. The model developed consists of three sub-models, namely the car-following, lane change and gap-acceptance. Some of these concepts are explained in the literature review section, but in this section, each sub-model will be addressed individually and the most important features of each model will be defined.

\subsubsection{Car-following rules}

For the sub-model of car-following, the safe distance model assumes that there is sufficient distance between a vehicle and another that prevents collisions in all traffic flows situations. Where it is highly efficient in the representation of reality, the reason is that it has been developed in many stages and different geometric sections of road (For example, roadworks section, weaving section, narrow lane section) and in the levels of microsimulation $[9,14,21,22]$.

Therefore, in this study will depend on the model developed by AL-Jameel [14], where AL-Jameel based on Benekohal [23] in the development of its model. This model consists of five cases of acceleration control of the longitudinal movement of the vehicle along the road and these accelerations are:

a. Acceleration of comfortable conditions.

b. Acceleration of the mechanical capability of the vehicle.

c. Acceleration to moving from stationary conditions.

d. Acceleration from slow moving conditions.

e. Acceleration of stopping the distance conditions.

One acceleration of these accelerations is used according to the situation in which the vehicle is selected and the appropriate acceleration is chosen according to a flowchart as Al-Jameel [24] note.

And then apply Equations ( 4 and 5 ) to update the location and speed of the vehicle every $0.5 \mathrm{sec}$ (scan time was adopted 0.5sec according to Alterawi [22]).

$$
\begin{aligned}
& \mathrm{SP}_{\text {Fnew }}=\mathrm{SP}_{\mathrm{F}}+\mathrm{ACL}_{\mathrm{F}}(\Delta \mathrm{t}) \\
& \mathrm{POS}_{\text {Fnew }}=\mathrm{POS}_{\mathrm{F}}+\mathrm{SP}_{\mathrm{F}}(\Delta \mathrm{t})+0.5 \mathrm{ACL}_{\mathrm{F}}(\Delta \mathrm{t})^{2}
\end{aligned}
$$

Where; $\mathbf{S P}_{\text {Fnew }}$ is the new speed $(\mathrm{m} / \mathrm{sec})$ and $\mathbf{P O S}_{\mathrm{Fnew}}$ is the new position $(\mathrm{m})$, of following vehicle at the end of the scan time interval.

$\mathbf{S P}_{\mathbf{F}}$ is the speed $(\mathrm{m} / \mathrm{sec})$ and $\mathbf{P O S}_{\mathrm{F}}$, is the position $(\mathrm{m})$ of following vehicle at the beginning of the scan time interval.

$\Delta t$ is the scanning time interval (sec), and

$A C L_{F}$ is the acceleration (or deceleration if negative) rate of following vehicle $\left(\mathrm{m} / \mathrm{sec}^{2}\right)$. 


\subsubsection{Lane change rules}

As for the sub-model of changing the lane, several hypotheses have been adopted to develop a model suitable for the behavior of the driver when changing the lane. As mentioned earlier in the literature review, the model of LC is divided into MLC and DLC, and since the study area is a normal section, the LC is the type DLC. Therefore, the type of DLC will be developed only in this study. The change of the lane either towards the right lane (i.e. the slower lane) or towards the left lane (i.e. the faster lane) will occur according to the driver's interaction and desire.

\subsubsection{LC to the left lane}

The driver changes his/her lane to the left lane to achieve a higher speed or to reach the desired speed in the case that it is preceded by a slow vehicle and this happens if one of the following conditions is met:

- If the speed of the driver's vehicle is higher than the speed of the vehicle preceded by the value of $\mathbf{R}$ (The value of $\mathbf{R}$ suggested by Ferrari [25]).

$$
R=1040 / \mathrm{SP}_{\mathrm{Fd}}
$$

Where; $\mathbf{S P}_{\mathrm{Fd}}$ desired speed $(\mathrm{km} / \mathrm{hr})$ of following vehicle.

- If the speed of the vehicle is less than the speed desired by the value of $R$ and the rules of the CF sub-model does not allow the speed increase and provided there is sufficient distance between the target vehicle and the new leader vehicle.

\subsubsection{LC to the right lane}

In the case of changing the corridor to the right, for example, occurs when the driver wants to return to the right lane after completing the process of overtaking and this is achieved if:

- The driver of the vehicle would prefer to change its lane to the right lane when its speed is less than the speed of the vehicle followed by the value of $\mathbf{R}$, provided that the speed of the vehicle is less than or equal to the speed desired.

- A change may occur towards the right lane when the right lane is empty for more than $300 \mathrm{~m}$ [26].

According to the field data, a percentage of drivers prefer to stay in the second lane, even if the first lane is free of vehicles for a long distance. This percentage ranges from 15 to 20 percent of users of the second lane, whether in the section with three lanes or two lanes. Figure 11 illustrates the flowchart of the process of changing the lane of the type DLC.

The change to another lane is made if the previous assumptions are satisfied and there is a motive for the driver to change his/her lane. The process of changing the lane is controlled by the critical gap. In order to the driver to safely change its path, this gap must be provided as shown in Equation 7 . To calculate this gap, either for lead or lag, Equation 1. and Equation 2. mentioned in the literary reviews are based.

$$
L G_{g} \geq L G_{g m i n} \quad \text { and } \quad L D_{g} \geq L D_{g m i n}
$$




\section{AL-QADISIYAH JOURNAL FOR ENGINEERING SCIENCES}

Vol. 10 , No. 4

ISSN: $1998-4456$

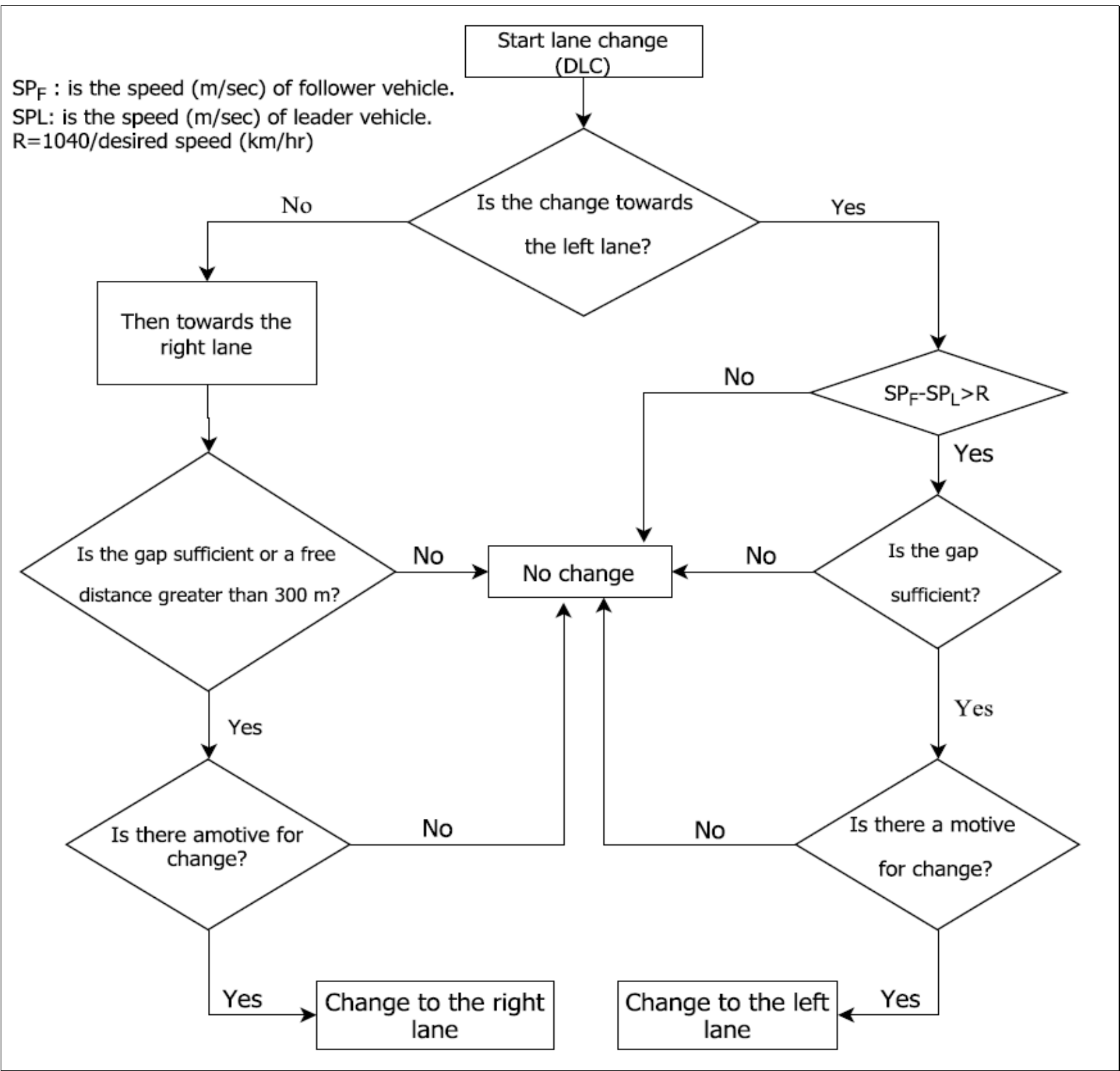

Figure 11: Flowchart for the process of changing the lane.

\section{CALIBRATION OF THE DEVELOPED MODEL}

After completing the development of the model it is important to conduct a calibration process in order to ensure that the model has the ability to represent the reality. The calibration includes checking the results of the model and comparing it with field data and correcting the parameters. This process is returned until the minimum amount of error allowed for the results of the model [27]. For the sub-model of car-following, it does not need to be calibrated at this stage of the research, but calibration will be done by comparing the traffic flow of the model results with the field data and also calibrating the sub-model of lane change.

The outputs of the model is the flow of traffic and frequency of lane change and many of the outputs can be used as needed, these outputs can be measured in the model by installing a virtual loop detector on a section of the road. Figure 12 shows the comparison between the results of the traffic flow of the model with the field data for a whole section of the road and Table 8 shows some statistical tests (see Equation 8. 
AL-QADISIYAH JOURNAL FOR ENGINEERING SCIENCES
Vol. 10, No. 4

ISSN: $1998-4456$

and 9.) Figure 13 shows a comparison between the modeling results and the field data for each lane and Table 9: proves this statistically.

$$
\begin{aligned}
& \mathrm{GEH}=\sqrt{\frac{2(y-x)^{2}}{y+x}} \\
& \mathrm{RMSEP}=\sqrt{\frac{1}{n} \sum_{i=1}^{n} \frac{\left(x_{i}-y_{i}\right)^{2}}{x_{i}}}
\end{aligned}
$$

The value of GEH is acceptable when it is less than 5, and if RMSEP value is less than or equal to 15, it is satisfactory (as mentioned by Alterawi (2014)).

Where; $n$ is the number of time intervals.

$x_{i}$ is the observed data at time interval $i$, and

$y_{i}$ is the simulated data at time interval $i$.

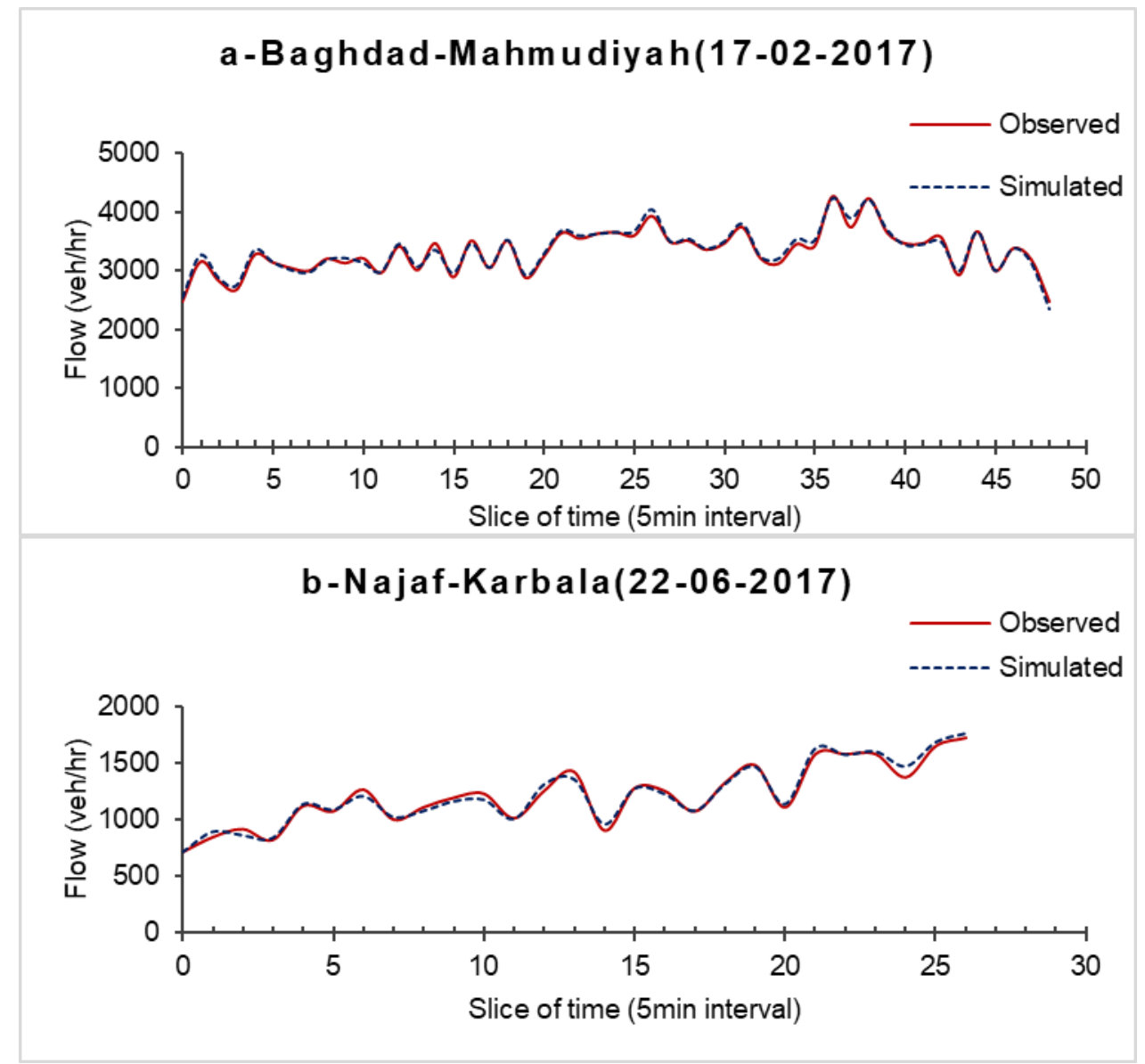

Figure 12: Traffic flow calibration, a-for a three-lane section, b- for a two-lane section. 
AL-QADISIYAH JOURNAL FOR ENGINEERING SCIENCES
Vol. 10 , No. 4

ISSN: $1998-4456$

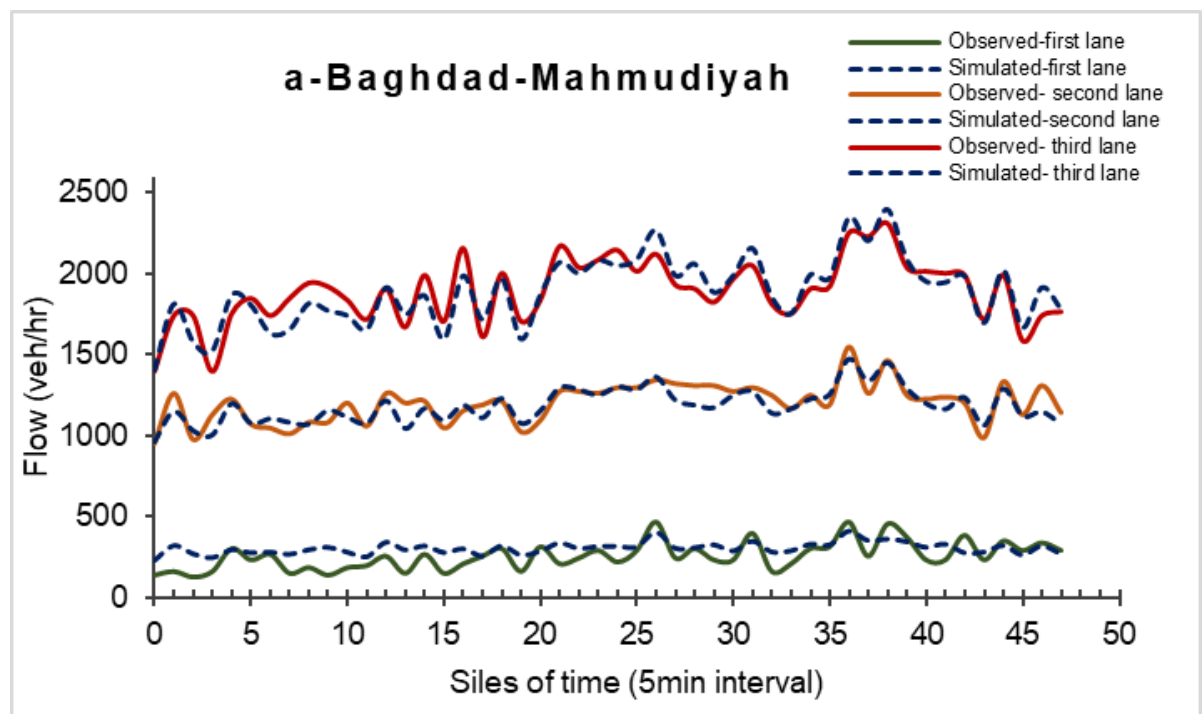

Figure 13-a: Traffic flow calibration, for a three-lane section.
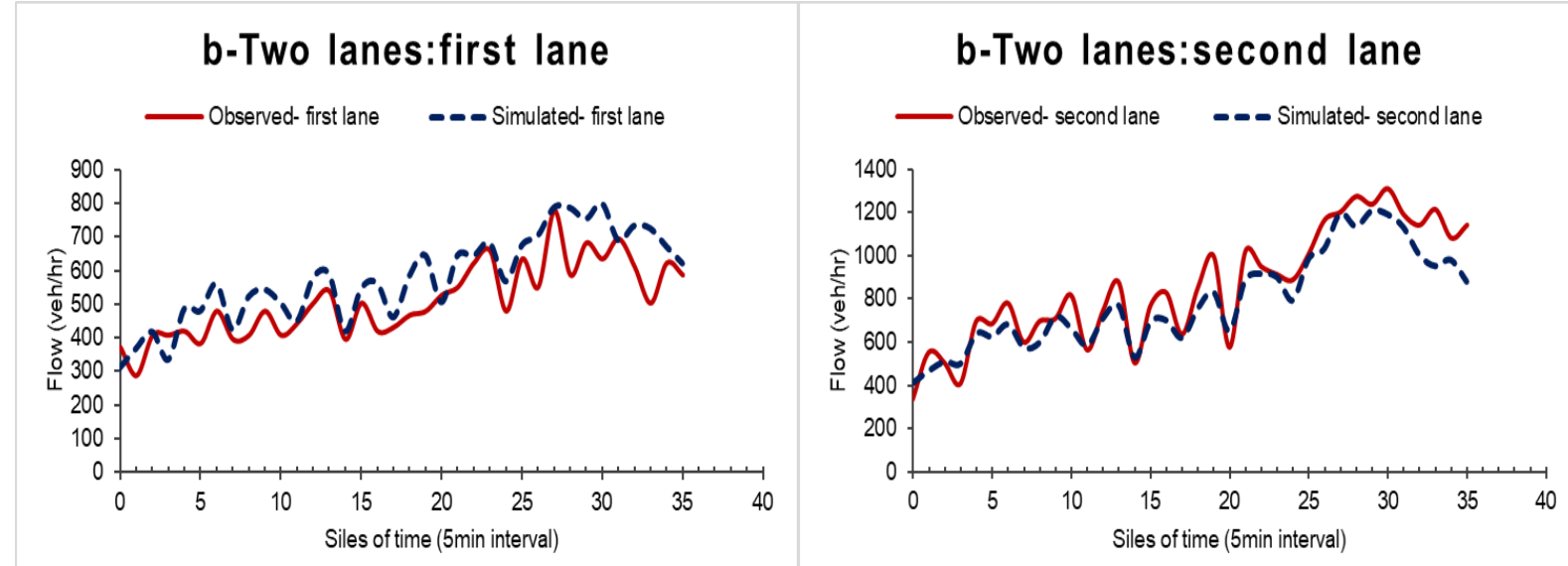

Figure 13-b: Traffic flow calibration, for a two-lane section (Najaf-Karbala).

Table 8: Calibration -statistical test results (flow for whole section).

\begin{tabular}{|c|c|c|}
\hline \multirow{2}{*}{ Section } & \multicolumn{2}{|c|}{ Statistical test } \\
\cline { 2 - 3 } & RMSEP\% $<15 \%^{*}$ & GEH $<5^{*}$ \\
\hline Three-lanes & 1.09 & 0.89 \\
\hline Two-lanes & 1.11 & 0.82 \\
\hline
\end{tabular}

*acceptable 


\section{AL-QADISIYAH JOURNAL FOR ENGINEERING SCIENCES}

Vol. 10 , No. 4

ISSN: $1998-4456$

Table 9: Calibration -statistical test results (flow for each lane).

\begin{tabular}{|c|c|c|c|}
\hline Section & Lane & RMSEP\% $<15 \%{ }^{*}$ & GEH $<5^{*}$ \\
\hline \multirow{3}{*}{ Three lanes } & First & 6.39 & 4.54 \\
\cline { 2 - 4 } & Second & 1.96 & 1.57 \\
\cline { 2 - 4 } & Third & 2.30 & 1.91 \\
\hline \multirow{2}{*}{ Two lanes } & First & 4.16 & 3.20 \\
\cline { 2 - 4 } & Second & 3.38 & 2.87 \\
\hline
\end{tabular}

As for the calibration of the model of lane change has been used frequency of lane change for calibrating. By means of gap-acceptance parameters (i.e. $\beta 1, \beta 2, \beta 3$, and $\beta 4$ ), the best results can be achieved between modeling and field data. Where a range of $(0.1,0.1,0.1$, and 0.1$)$ to $(1,1,1,1)$ was used for these parameters and using several runs and resetting of these parameters until the best values required for these parameters were achieved: $(0.3,0.6,0.4,0.7)$ for a three-lane section and $(0.4,0.8,0.6,0.5)$ for a two-lane section, where Figure 14 compares graphically between modeling results and field data. The results show good consistency between the simulated and field data.
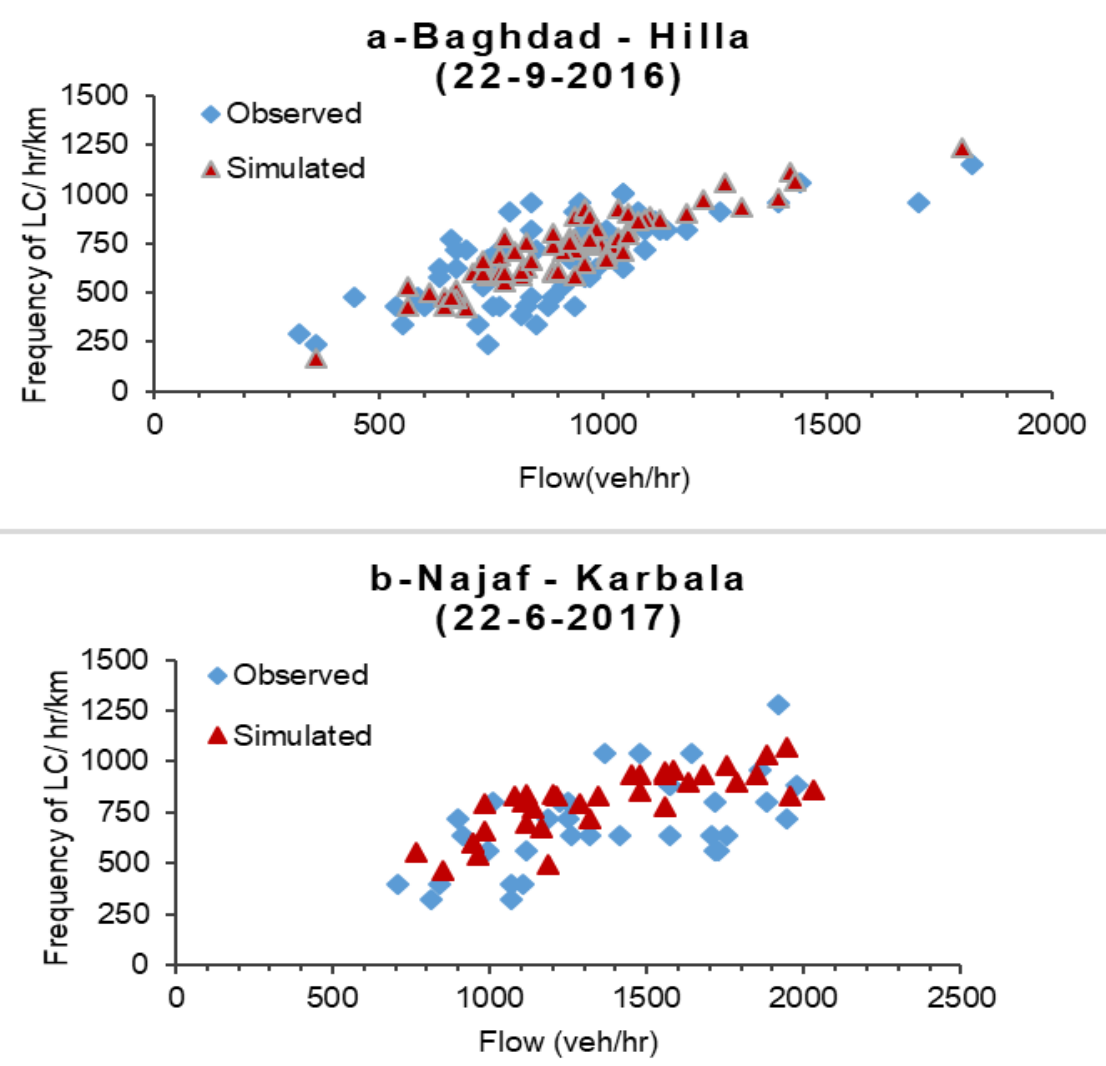

Figure 14: Comparison of frequency of lane change for modeling results with field data,a-for a three-lane section, b- for a two-lane section.

\section{VALIDATION OF THE DEVELOPED MODEL}

After completing the calibration process, the model needs an additional testing process with other data. Validation process is the stage of ascertaining the viability of the model to conduct and achieve several applications. 


\section{AL-QADISIYAH JOURNAL FOR ENGINEERING SCIENCES}

Vol. 10, No. 4

ISSN: $1998-4456$

Figure 15 shows the process of comparison between the flow of the results of the model and actual data for whole model and Table 10 shows that the modeling results match very acceptable with reality through statistical tests. As for the results of the speed, the model has the ability to calculate the speed for each lane, but cannot be measured realism speed with high accuracy acceptable by speed gun and for all vehicles, where the speed gun has the ability to measure the speed of one vehicle during each run of the device (speed gun). Therefore, the calibration and validation of the flow of traffic were conducted only. Figure 16 shows the comparison of frequency of lane change (FLC) of modeling with FLC of the field data.

Table 10: Validation-statistical test results.

\begin{tabular}{|c|c|c|}
\hline \multirow{2}{*}{ Section } & \multicolumn{2}{|c|}{ Statistical test } \\
\cline { 2 - 3 } & RMSEP\% $<15 \%^{*}$ & $\mathrm{GEH}<5^{*}$ \\
\hline Three lanes & 2.34 & 1.56 \\
\hline Two lanes & 1.55 & 1.14 \\
\hline
\end{tabular}

*acceptable

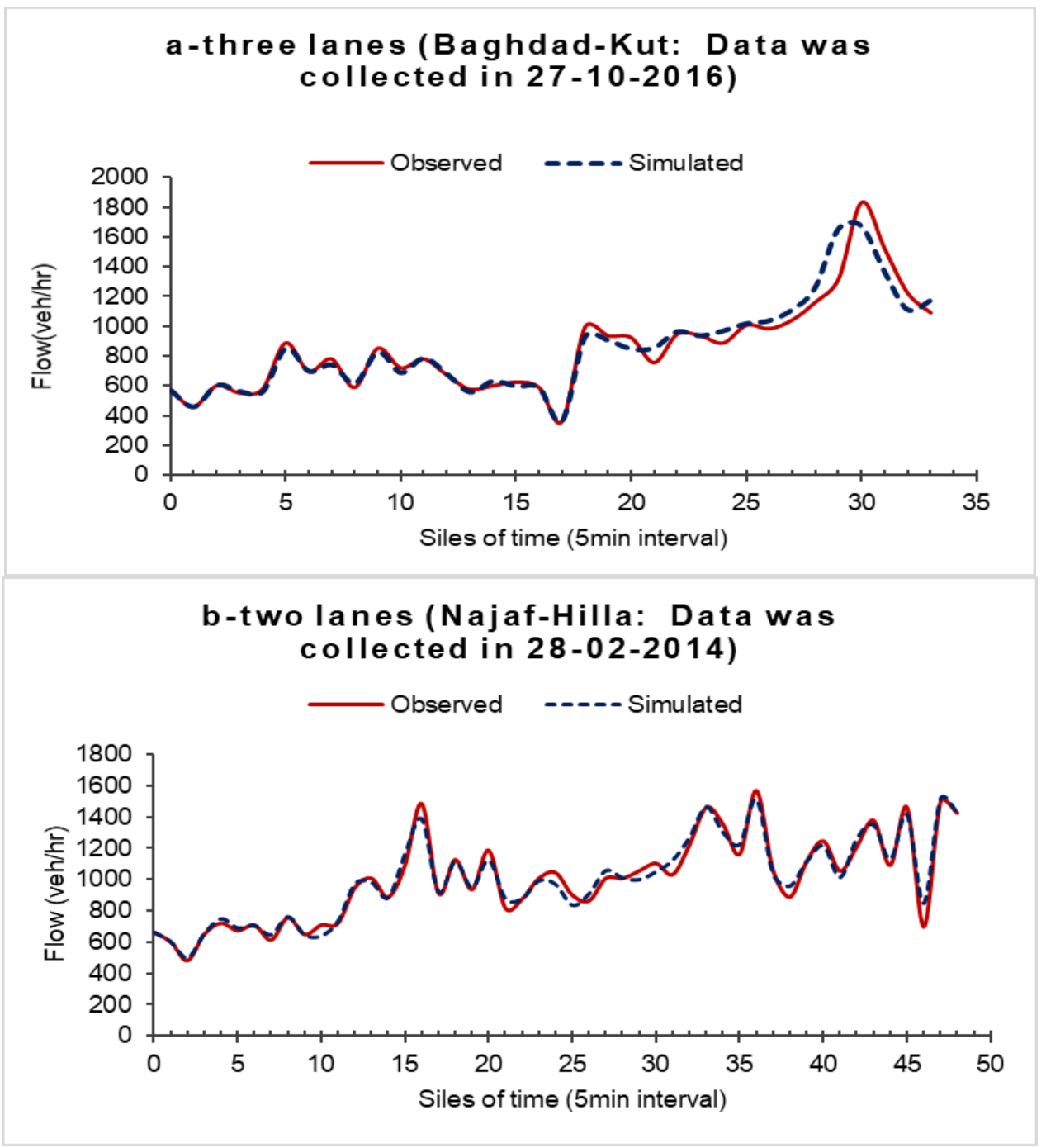

Figure 15: Traffic flow validation, a-for a three lanes, b- for a two lanes. 


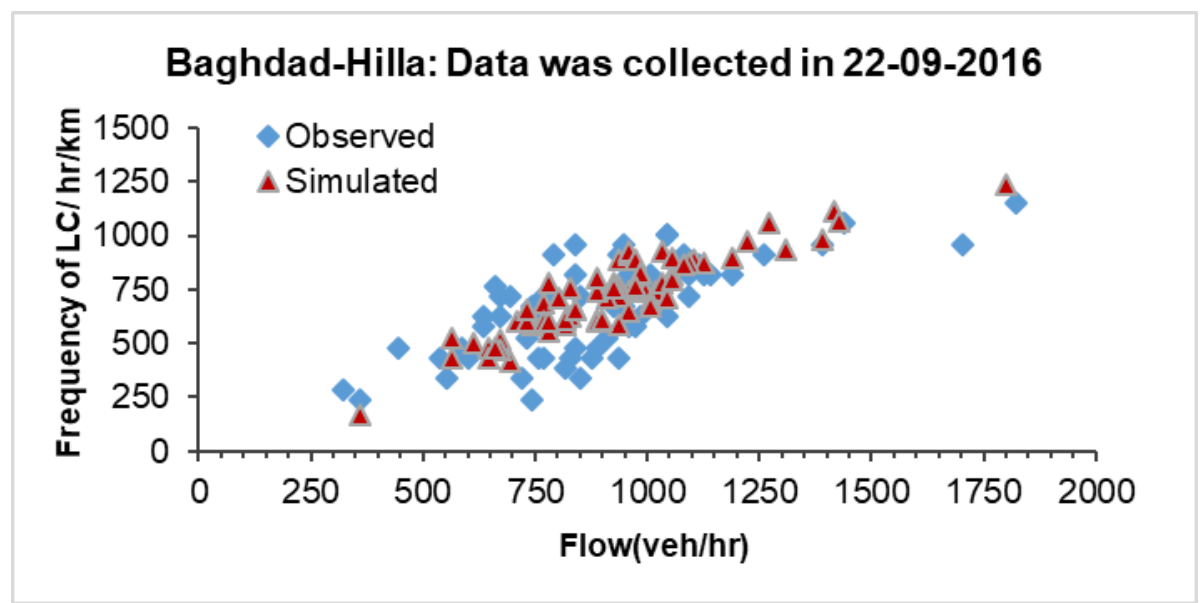

Figure 16: Comparison of frequency of lane change for model results with actual data.

\section{CONCLUSIONS}

The main conclusions that could be summarized from this study are:

1. Huge amount of field data have been collected for rural roads which could be used as calibrated parameters for the developed simulation model.

2. The lane utilization has been investigated for three and two lane sections. It was found that most drivers prefer to be in the high speed lane.

3. Other data have been investigated such as headway. It was found that negative exponential distribution is the best one to fit the headway character. Moreover, normal distribution was found the best for desired speeds at rural roads.

4. The LC developed model, which is the sub-model, has considered more Iraqi driver behavior during the process of its developing.

5. The developed model shows good consistency with field data which is the most important stage before using such model to study different traffic characteristics. The calibrated characteristics were flow and LCs.

\section{BIODATA}

- Dr. Hamid Athab Al-Jameel is Assistant Professor at the Faculty of Engineering, Department of Civil Engineering, University of Kufa. Email; Hamid.aljameel@uokufa.edu.iq.

- Eng. Ali Jihad Kadhim is a Master student in the Faculty of Engineering, Highways and Transportation Engineering Dep., Al-Mustansiriayah University. Email; Alijkr1993@gmail.com.

\section{REFERENCES}

1. Liu, A. and D. Salvucci. Modeling and prediction of human driver behavior. in Intl. Conference on HCl. 2001.

2. BERNHARD, M. and K. SCHMEIDLER, The Influence of In-Vehicle Information Systems on Driver Behaviour and Road Safety: COST Action 352. Brno: Ing. Zdeněk Novotný, 2009. 89 p. 2007, ISBN 978-80-7355-083-7.

3. Ahmed, K.I., Modeling drivers' acceleration and lane changing behavior. 1999, Massachusetts Institute of Technology.

4. Elefteriadou, L., Modeling Vehicle Interactions and the Movement of Groups of Vehicles, in An Introduction to Traffic Flow Theory. 2014, Springer. p. 31-58. 


\section{AL-QADISIYAH JOURNAL FOR ENGINEERING SCIENCES}

Vol. 10, No. 4

ISSN: $1998-4456$

5. Wood, S., Traffic microsimulation-dispelling the myths. Traffic Engineering and Control, 2012. 53(9): p. 339-344.

6. Lidbe, A.D., A.M. Hainen, and S.L. Jones, Comparative study of simulated annealing, tabu search, and the genetic algorithm for calibration of the microsimulation model. Simulation, 2017. 93(1): p. 2133.

7. Gipps, P.G., A behavioural car-following model for computer simulation. Transportation Research Part B: Methodological, 1981. 15(2): p. 105-111.

8. Benekohal, R. and J. Treiterer, CARSIM: Car-following model for simulation of traffic in normal and stop-and-go conditions. Transportation research record, 1988(1194).

9. Yousif, S.Y., Effect of lane changing on traffic operation for dual carriageway roads with roadworks. 1993, University of Wales. Cardiff.

10. Al-Jameel, H.A., Evaluation of car-following models using field data. 2010.

11. Xiaorui, W. and Y. Hongxu, A lane change model with the consideration of car following behavior. Procedia-Social and Behavioral Sciences, 2013. 96: p. 2354-2361.

12. Rahman, M., et al., Review of microscopic lane-changing models and future research opportunities. IEEE transactions on intelligent transportation systems, 2013. 14(4): p. 1942-1956.

13. Wang, J., A merging model for motorway traffic. 2006, The University of Leeds.

14. Al-Jameel, H.A.E., Developing a simulation model to evaluate the capacity of weaving sections. 2012, University of Salford.

15. Guo, R.-j., X.-j. Wang, and W.-x. Wang, Estimation of critical gap based on Raff's definition. Computational intelligence and neuroscience, 2014. 2014: p. 16.

16. Duncan, G. PARAMICS wide area microscopic simulation of ATT and traffic management. in Proceedings of the 28th International Symposium on Automotive Technology and Automation (ISATA). 1995.

17. Li, L. and X.M. Chen, Vehicle headway modeling and its inferences in macroscopic/microscopic traffic flow theory: A survey. Transportation Research Part C: Emerging Technologies, 2017. 76: p. 170-188.

18. ITE, I.o.T.E., Traffic Engineering Handbook. 1999.

19. Johansson, G. and K. Rumar, Drivers' brake reaction times. Human Factors: The Journal of the Human Factors and Ergonomics Society, 1971. 13(1): p. 23-27.

20. Mutlu Aydin, M. and A. Topal, Effect of road surface deformations on lateral lane utilization and longitudinal driving behaviours. Transport, 2016. 31(2): p. 192-201.

21. Al-Obaedi, J.T.S., Development of traffic micro-simulation model for motorway merges with ramp metering. 2012, University of Salford.

22. Alterawi, M., Development of a micro-simulation model to evaluate shuttle-lane roadwork operations. 2014, University of Salford.

23. Benekohal, R.F., Development and validation of a car following model for simulation of traffic flow and traffic wave studies at bottlenecks. 1986, The Ohio State University.

24. Al-Jameel, H.A., Developing a New Hybrid Safety Car-following Model. Kufa journal of Engineering, 2014. 5(2).

25. Ferrari, P., The effect of driver behaviour on motorway reliability. Transportation Research Part B: Methodological, 1989. 23(2): p. 139-150.

26. Sultan, B. and M. McDonald, THE LANE CHANGING PROCESS: DATA ANALYSIS AND MODELLING BEHAVIOUR. Traffic Engineering \& Control, 2001.

27. Chu, L., et al. A calibration procedure for microscopic traffic simulation. in Intelligent Transportation Systems, 2003. Proceedings. 2003 IEEE. 2003. IEEE. 